\title{
Visible Light-Induced Superior Photocatalytic Activity of Ag@Nd2WO6/ZnO Nanocomposite and its Biological Activity
}

\author{
Arunpandian. M, Selvakumar K, Nagarajan E. R, Arunachalam. S
}

\begin{abstract}
In this work, degradation of Ciprofloxacin has been studied over the catalyst $\mathrm{Ag} @ \mathrm{Nd} 2 \mathrm{WO6} / \mathrm{ZnO}$ (ANWZ) synthesized via hydrothermal method. The catalysts are characterized with techniques such as X-ray diffractometer, Scanning electron microscope with EDX spectroscopy and DRS- UV spectroscopy respectively. For the results shows, the PXRD spectroscopy was confirmed a phase purity and crystalline structure of the as-synthesized catalyst. The SEM results are explained about the morphology structure of the material, the structure spherical with nanorod like clustered morphology structure was shown in SEM and the reacting elements in the catalytic material are confirmed by EDX spectroscopy. And the DRS-UV spectroscopy technique is telling about the band energy value for prepared materials and also select the suitable way (i.e: Visible or UV light irradiation) for the degradation. The photocatalytic process, Ciprofloxacin (CIP) drug are degraded under visible light within 140 minutes and the degradation efficiency are $95.54 \%$. The reusability test explains the efficiency and stability of the ANWZ catalyst and its stable up to the fifth run. Further, the photodegradation process, the catalyst is tested antibacterial activity study against Bacillus cereus and Escherichia Coli bacterial organisms. From the result, Bacillus bacteria contain more efficient antibacterial activity than that of E.coli bacteria.
\end{abstract}

Keywords: Catalytic degradation, Ciprofloxacin, Silver doped metal tungstate, visible light, Biological study

\section{INTRODUCTION}

Currently, the water crisis is a major problem for human beings and other organisms. In around the world highly amount of water is surrounded by the resources of the ocean, lake, river and pond. In the modern world lacs and lacs of medicinal products, cosmetics, chemicals and colouring agents are used by human beings. All the products are prepared via industries and the wastes are not removed properly. But these wastes are directly discharged to the environmental water resources and also polluted. This polluted water is not used to drinking for living organisms. Besides, it affected by human beings and animals [1].

Revised Manuscript Received on December 09, 2019.

* Correspondence Author

M. Arunpandian, Nanomaterials Laboratory, Department of Chemistry, International Research Centre, Kalasalingam Academy of Research and Education (Deemed to be University), Krishnankoil - 626126, India. Email: arunpandiantt126@gmail.com

K. Selvakumar, Nanomaterials Laboratory, Department of Chemistry, International Research Centre, Kalasalingam Academy of Research and Education (Deemed to be University), Krishnankoil - 626126, India. Email: selvachemistk@gmail.com

E. R. Nagarajan, Nanomaterials Laboratory, Department of Chemistry, International Research Centre, Kalasalingam Academy of Research and Education (Deemed to be University), Krishnankoil - 626126, India. Email: nagarajanklu@gmail.com

S. Arunachalam*, Nanomaterials Laboratory, Department of Chemistry, International Research Centre, Kalasalingam Academy of Research and Education (Deemed to be University), Krishnankoil - 626126, India. Email: drarunachalam.s@gmail.com
Nowadays all the polluted water are involved in treating process by the conventional, physical and chemical method [2]. In this process, the polluted water is not treated completely. But in the eco-friendly Advanced oxidation process, including photocatalytic degradation, can do remove the waste materials, pharmaceutical drugs and the dyes waste from the pollutant water. The catalytic degradation is a predominant process and has been good remediation for the environment to the removing of a pollutant from the wastewater. In this work, the antibiotic (Ciprofloxacin (CIP)) was degraded by ANWZ nanomaterial. The CIP antibiotic has a main pollutant material in the hospital waste and it is a great threat for humans and the animal's health $[3,4]$.

Among, heterogeneous semiconductor photocatalysis by inexhaustible solar light as a driving force has one of the great potential processes, to degrade the CIP pollutants [5]. Compare to the degradation of dyes and other pollutants, CIP antibiotic degradation is relatively very difficult [6-8]. In this work, $\mathrm{Ag} @ \mathrm{Nd} 2 \mathrm{WO} 6 / \mathrm{ZnO}$ (ANWZ) nanocomposite is the semiconductor materials have been used to degrade the pollutants. From this nanocomposite, the doped rare-earth tungstates are used for luminescent applications and are also used for fabrication of white light-emitting diodes for high stability and energy-saving [9]. By the quantum confinement effects the semiconductor of $\mathrm{ZnO}$ having some optical properties [10]. The $\mathrm{ZnO}$ is used in the field of catalysts, surface wave acoustic devices, cancer-detecting biosensors, degradation of organic pollutants etc., [11-12]. The $\mathrm{Ag} @ \mathrm{Nd} 2 \mathrm{WO6} / \mathrm{ZnO}$ nanoparticles are successfully prepared via the hydrothermal method and it having a good ability and highly eminent properties in the catalytic degradation process. The synthesis of nanomaterials is confirmed by Scanning electron microscope (SEM) with EDX spectroscopy, X-Ray diffractometer spectroscopy and DRS-UV spectroscopy. The degradation of pollutant is detected by UV-Visible spectroscopy technique.

\section{AN ANTIBACTERIAL STUDY BY DISC DIFFUSION METHOD}

The antibacterial study is processing under the disc diffusion method by $\mathrm{Ag} @ \mathrm{Nd}_{2} \mathrm{WO}_{6} / \mathrm{ZnO}$ nanocomposite. The zones of inhibition diameter of the disc are measured by this method. Lucia agar plates were prepared and by Luria-Bertani medium (Becton Dickinson) surface the culture of Bacillus and E.coli $(50 \mu \mathrm{l}, 100 \mu \mathrm{l})$ were swabbed in overnight. The disc is commercially prepared which can impregnate with a standard concentration of nanoparticles and slightly pressed the agar surface. 
The plates were incubated at $37^{\circ} \mathrm{C}$ in one day for the diffusion of the sample into the agar medium. The negative and the positive control for the bacterial system are chloramphenicol (pharmaceutical material) and the distilled water. The formation of an inhibition zone is around the well was measured the biological activity [13].

\section{MATERIALS AND METHODS}

\section{A. Materials and characterization}

Sodium tungstate, silver nitrate, Neodymium acetate, Zinc acetate is the major precursor's materials for preparation and is purchased from Sigma Aldrich chemicals. Oxalic acid, Sodium hydroxide, Ciprofloxacin drug are the other sources for a reaction. All the solutions are prepared by double distilled water. The prepared materials are further confirmed by the following characterization techniques. The Scanning electron microscope (EVO-80, CARL ZEISS) spectroscopy predicts the morphology structure of the material and the EDX (AMETEK-EDAX (Z2e Analyzer)) spectroscopy is confirms the presenting elements for the nanocomposite. Powder X-ray diffraction (PXRD) (Shimadzu XRD-6000 $\mathrm{X}$-ray diffractometer $(\mathrm{Cu} \mathrm{K \alpha}$ source $))$ is the crystalline structure of the sample. The band energy values are analyzed by UV-Vis diffuse reflection spectroscopy (DRS) Shimadzu UV-2450 spectrophotometer. The UV-visible spectroscopy (Shimadzu UV-1800) is used to find the absorbance value for degradation samples.

\section{B. Synthesis of Materials \\ Synthesize of Nd2WO6/ZnO (NWZ)}

Na2WO4 $(0.05 \mathrm{M})$ was mixed with $100 \mathrm{~mL}$ of deionized water with constant stirring, to this solution $\mathrm{Nd}$ (CH3CO2)3.xH2O (6mmol) (in $100 \mathrm{ml}$ water) solution was added at room temperature. The $\mathrm{pH}$ was adjusted to 10 by adding $\mathrm{NaOH}$ for the complete precipitation. From the above suspension mixture $100 \mathrm{~mL} 0.4 \mathrm{M} \mathrm{Zn}(\mathrm{CH} 3 \mathrm{CO} 2) 2 \cdot 2 \mathrm{H} 2 \mathrm{O}$ solution was added slowly and agitate for $30 \mathrm{~min}$. After stirring $100 \mathrm{~mL}$ of oxalic acid $(0.6 \mathrm{M})$ solution was added with drop wisely and continued stirring for $4 \mathrm{~h}$. After the completion, the colloidal mixer was transferred into a Teflon lined stainless steel autoclave at $150^{\circ} \mathrm{C}$ for $16 \mathrm{hrs}$. After treating, the collected samples were dried in an oven at $70^{\circ} \mathrm{C}$ for $12 \mathrm{~h}$ and annealed at $550{ }^{\circ} \mathrm{C}$ for $8 \mathrm{hrs}$ in a muffle furnace.

\section{Synthesize of Ag@ Nd2WO6/ZnO (ANWZ)}

The ANWZ (1mmol) photocatalyst and silver nitrate $(0.5$ mmol) precursor are mixed in $100 \mathrm{ml}$ of deionized water with a Stoichiometry ratio, the reducing agent sodium borohydride are introduced with drop by drop to the above solution. And subsequently, the solution was allowed to cool at room temperature. After cooling in some time the precipitate was formed. The formed precipitate was collected by filtration and washed with water and ethanol to four times. After the washing, the collected precipitate was dried in a vacuum oven at $60^{\circ} \mathrm{C}$ at overnight. Finally, the dry samples are annealed at $650^{\circ} \mathrm{C}$ for $8 \mathrm{~h}$ in a furnace.

\section{Photocatalytic experiments}

In the photocatalytic degradation process, Heber multi-lamp as a (tungsten lamp light source with the intensity is $150 \mathrm{~mW} / \mathrm{cm}^{-2}$ ) photoreactor for the degradation of CIP drug under visible light $(\lambda>400 \mathrm{~nm})$ irradiation by ANWZ. $40 \mathrm{mg}$ of the catalyst are taken in a $250 \mathrm{ml}$ beaker and it mixed in
$100 \mathrm{ml}$ CIP solution with $40 \mu \mathrm{m}$ concentration And it stirred for $30 \mathrm{~min}$ in dark room, to ensure the adsorption-desorption equilibrium of the reaction solution. After that, the colloidal solution was transferred into a reaction vessel. After in between the reaction $5 \mathrm{~min}$ time intervals, $5 \mathrm{ml}$ of the reaction solution was collected purely by centrifuged and monitored the absorption peak of CIP at $272 \mathrm{~nm}$ using UV visible spectrometer. The completion of the degradation reaction, reacting catalyst was separated by an ultracentrifuge, and it washed with de-ionized water for three times and dried at $60^{\circ} \mathrm{C}$. Finally, it is introduced to the reusability test again and again for five cycles.

\section{RESULTS AND DISCUSSIONS}

\section{A. Powder X-Ray Diffractometer Spectroscopy}

In PXRD spectroscopy, the crystalline structure and the phase purity of the sample are analyzed by the range between $10-80^{\circ}$. From Fig. 1 shows the results of PXRD spectrum for $\mathrm{ZnO}, \mathrm{Nd}_{2} \mathrm{WO}_{6}, \mathrm{Ag} @ \mathrm{Nd}_{2} \mathrm{WO}_{6} / \mathrm{ZnO}$ nanocomposites. The main observed peaks in the $2 \theta$ range $\mathrm{Nd}_{2} \mathrm{WO}_{6}$ at 24.18 , $27.89,28.38,31.54,32.39,33.88^{\circ}$ which resembled to the ( $\overline{1} 11),(\overline{1} 1)$, (121), (040), (200) and (002) planes of monoclinic structure belongs to I2/a space group of $\mathrm{Nd}_{2} \mathrm{WO}_{6}$ (JCPDS no. 22-1180)

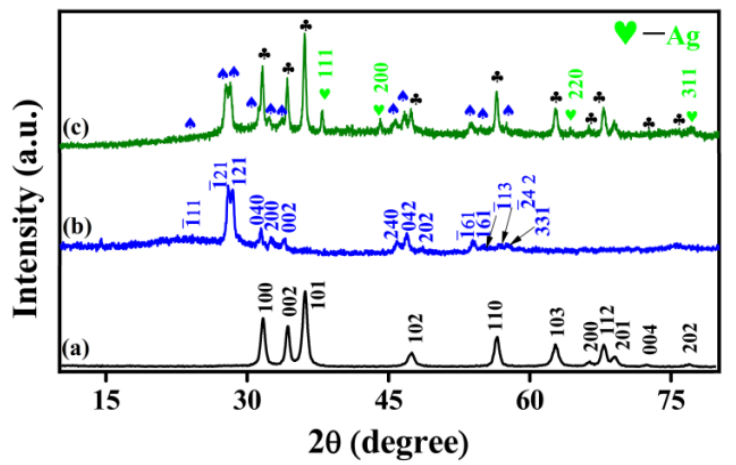

Fig. 1 X-ray diffraction for a) $\mathrm{ZnO}$, b) $\mathrm{Nd} 2 \mathrm{WO6}$, c) $\mathrm{Ag} /$ Nd2WO6-ZnO nanocomposite

In Nd2WO6 spectrum there is no impurity peak was observed because it formed clearly. For Ag (JCPDS 89-3722), the observed peaks $38.1,44.5,64.5$ and 77.60 are confirmed by the formation of silver to the nanocomposites with Cubic structure system. The PXRD spectrum of $\mathrm{ZnO}$ is confirmed by the JCPDS - 36-1451. The main diffraction peaks are observed at $31.6,34.23,36.18,47.38^{\circ}$ respectively. In $\mathrm{ANWZ}$ nanocomposite, the intense peak of $\mathrm{Ag}, \mathrm{ZnO}$, and the $\mathrm{Nd}_{2} \mathrm{WO}_{6}$ represents the complete formation.

\section{B. Scanning Electron Microscope and EDX Spectroscopy}

The morphology structure of the prepared nanocomposites is analyzed by Scanning electron microscope techniques and it is shown in Fig. 2. The $\mathrm{Nd}_{2} \mathrm{WO}_{6}$ (Fig. 2a) nanoparticles having the nanorods structure and the $\mathrm{ZnO}$ exhibits hexagonal like clustered structure (Fig. 2b). And, the $\mathrm{Nd}_{2} \mathrm{O}_{3}-\mathrm{ZnO}$ particles are shown in the cluster with nanorods (Fig. 2c) structure. In $\mathrm{Ag} @ \mathrm{Nd}_{2} \mathrm{WO}_{6} / \mathrm{ZnO}$ nanocomposite, the spherically structure of silver particles (mentioned by yellow round) is anchored on a cluster with nanorods structure in Fig. 2d\&e. 
The presenting elements like $\mathrm{Ag}, \mathrm{Nd}, \mathrm{W}, \mathrm{Zn}, \mathrm{O}$ and $\mathrm{C}$ in $\mathrm{Ag} @ \mathrm{Nd}_{2} \mathrm{WO}_{6} / \mathrm{ZnO}$ were analyzed by EDX spectrum. It is evidence for the complete formation of nanocomposites.
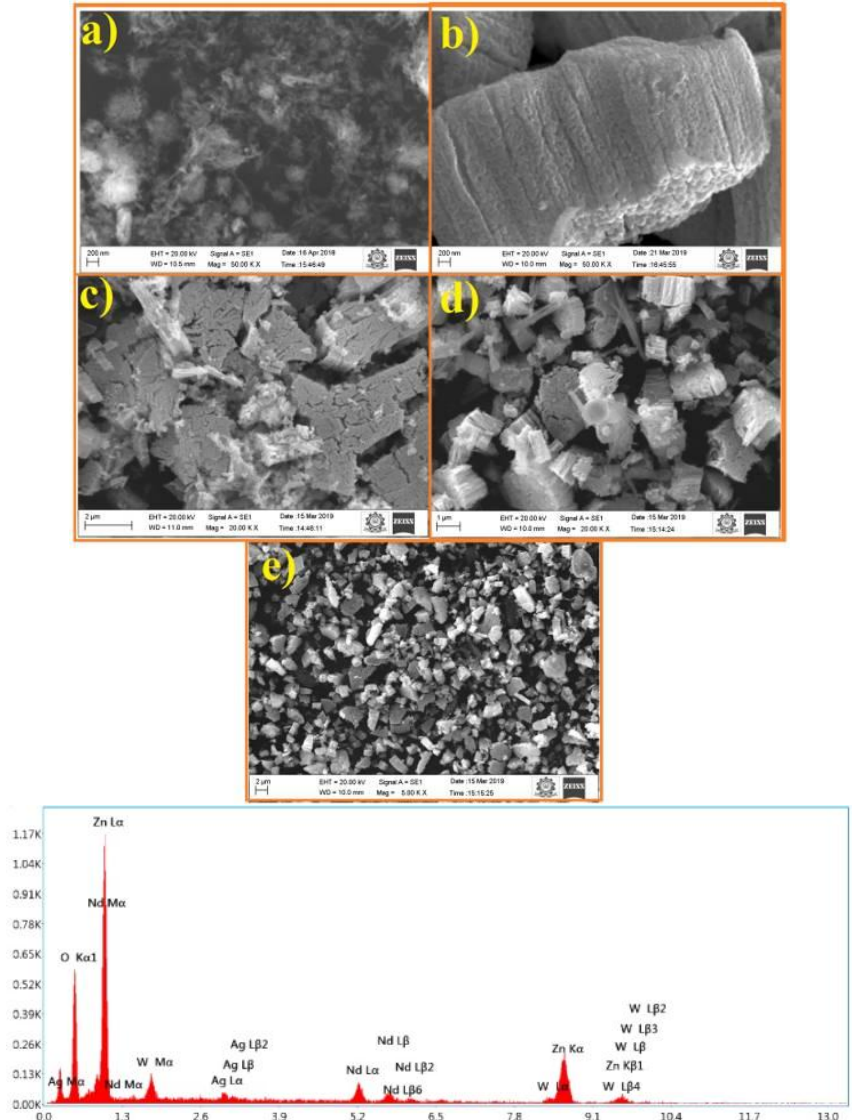

Fig. 2 SEM images of a) Nd2WO6, b) $\mathrm{ZnO}$, c) Nd2WO6/ZnO, (d, e) Ag@Nd2WO6/ZnO with different magnification range and the EDX Spectroscopy of the prepared nanocomposite

\section{DRS- UV spectroscopy}

In general, the band energy value can help the degradation process to find a suitable light needed for the degradation of CIP.

DRS-UV spectrum is used to measured band gap value and is shown in Fig - 3. It represents the diffuse reflectance absorption spectra of $\mathrm{NW}, \mathrm{ZnO}$, and $\mathrm{ANWZ}$ respectively. The bandgap value is calculated between $(\alpha h \gamma)^{\wedge^{2}}$ is and the photon energy (h $\gamma$ ). The bandgap Value for $\mathrm{NW}$ is $3.85 \mathrm{eV}$, $\mathrm{ZnO} 3.24 \mathrm{eV}$ and the ANWZ values are $2.72 \mathrm{eV}$. The bandgap energy decreased from $3.85 \mathrm{eV}$ to $2.72 \mathrm{eV}$. These indicate the ANWZ photocatalyst are carried out the degradation process by visible light irradiation.

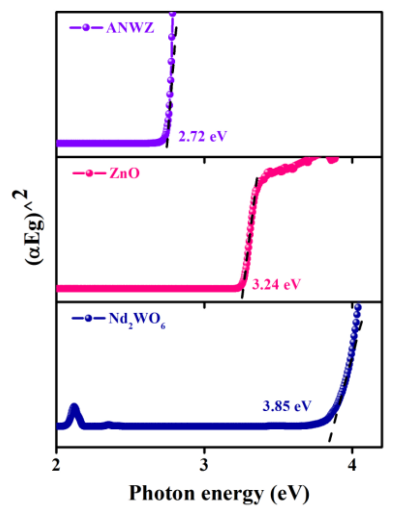

Fig. 3 DRS-UV spectrum for NW, ZnO and ANWZ

\section{Antibacterial activity test}

The catalyst ANWZ is used to study the antibacterial study by disc diffusion method. The activity was studied against the Gram-negative bacteria (E.Coli) and Gram-positive bacteria (Bacillus). From Fig. 4 the Zone image is obtained by the ANWZ composite, the positive control is a standard (chloramphenicol) and the negative control is distilled water. From the results, the Zone image of two bacteria by ANWZ composite with different concentration, the Zone surface area of Bacillus is higher in $100 \mu \mathrm{g} / \mu \mathrm{L}$ concentration compare to $50 \mu \mathrm{g} / \mu \mathrm{L}$ concentration of composite and the two different concentrations of E.Coli bacteria. Therefore antibacterial activity is much more in Bacillus with $100 \mu \mathrm{g} / \mu \mathrm{L}$ concentration is noticed.

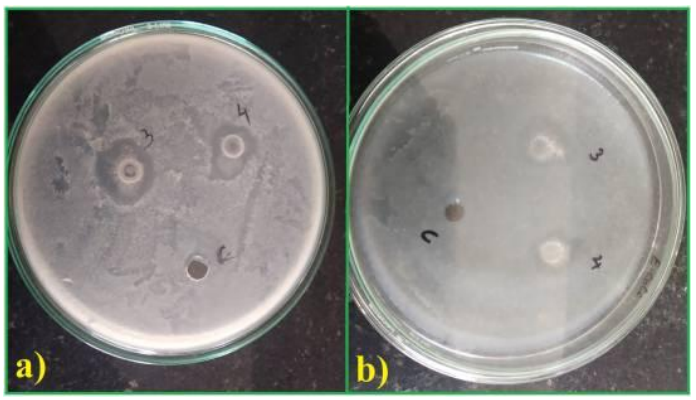

Fig. 4 Antibacterial study: The inhibition of Zone image photographs of Bacillus and E.coli bacterias with different concentration

Table 1: Biological (Antibacterial activity) study of Ag@Nd2WO6/ZnO nanocomposite

\begin{tabular}{|c|c|c|c|}
\hline \multirow{2}{*}{ Catalyst } & \multirow{2}{*}{$\begin{array}{c}\text { Concentration } \\
\mu \mathbf{g} / \mu \mathbf{L}\end{array}$} & \multicolumn{2}{|c|}{$\begin{array}{c}\text { Zone inhibition in } \\
\mathbf{m m}\end{array}$} \\
\cline { 3 - 4 } & $\begin{array}{c}\text { Escherichia } \\
\text { coli }\end{array}$ & $\begin{array}{c}\text { Bacillus } \\
\text { cereus }\end{array}$ \\
\hline $\begin{array}{c}\mathrm{Ag} @ \mathrm{Nd}_{2} \mathrm{WO}_{6} / \mathrm{ZnO} \\
(\mathrm{ANWZ})\end{array}$ & 50 & $+(06)$ & $+(09)$ \\
\cline { 2 - 4 } & 100 & $+(08)$ & $+(12)$ \\
\hline $\begin{array}{c}\text { Standard } \\
(\text { Chloramphenicol })\end{array}$ & 100 & $+(13)$ & $+(15)$ \\
\hline
\end{tabular}

+ : No growth observed (active of the compound is more against organisms)

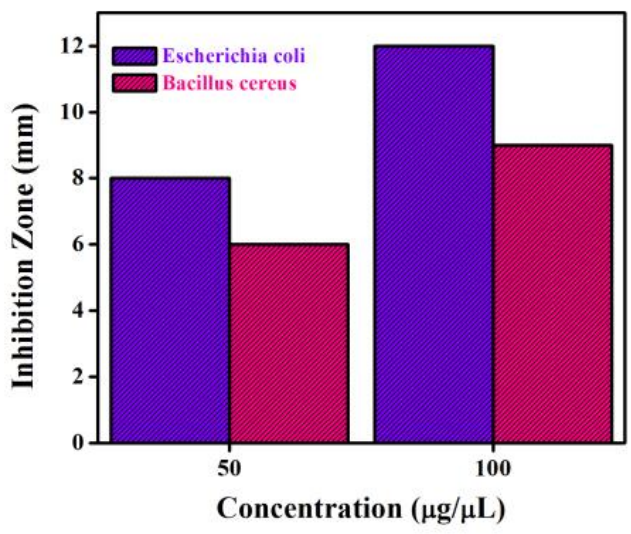

Fig.5 Bacterial growth inhibition zone by Ag@Nd2WO6/ZnO catalyst at various pathogens

From table 1 represents the value for the zone of inhibition in $\mathrm{mm}$ for the two bacteria's. In Fig. 5 the bacterial growth of the zone of inhibition at various pathogens are seen. 


\section{PHOTOCATALYTIC DEGRADATION OF CIP}

\section{A. The optimization of different catalyst usage}

The suitable reaction conditions for the degradation process are catalyst dosage, optimization concentration of CIP and efficient of different catalyst. The different catalyst $\mathrm{ZnO}, \mathrm{Nd}_{2} \mathrm{WO}_{6}, \mathrm{Nd}_{2} \mathrm{WO}_{6} / \mathrm{ZnO} \& \mathrm{Ag} @ \mathrm{Nd}_{2} \mathrm{WO}_{6} / \mathrm{ZnO}$ and without catalyst are degraded under visible light within 140 minutes. Compare to the different catalyst the efficiency is higherin $\mathrm{Ag} @ \mathrm{Nd}_{2} \mathrm{O}_{3} / \mathrm{ZnO}$ nanocomposite than that of others. After the degradation is completed, the $\mathrm{C} / \mathrm{C}_{0}$ values are reaching almost zero. The absorption spectrum of CIP degradation is seen in Fig. 5(ii) and the absorption value is $272 \mathrm{~nm}$ respectively.
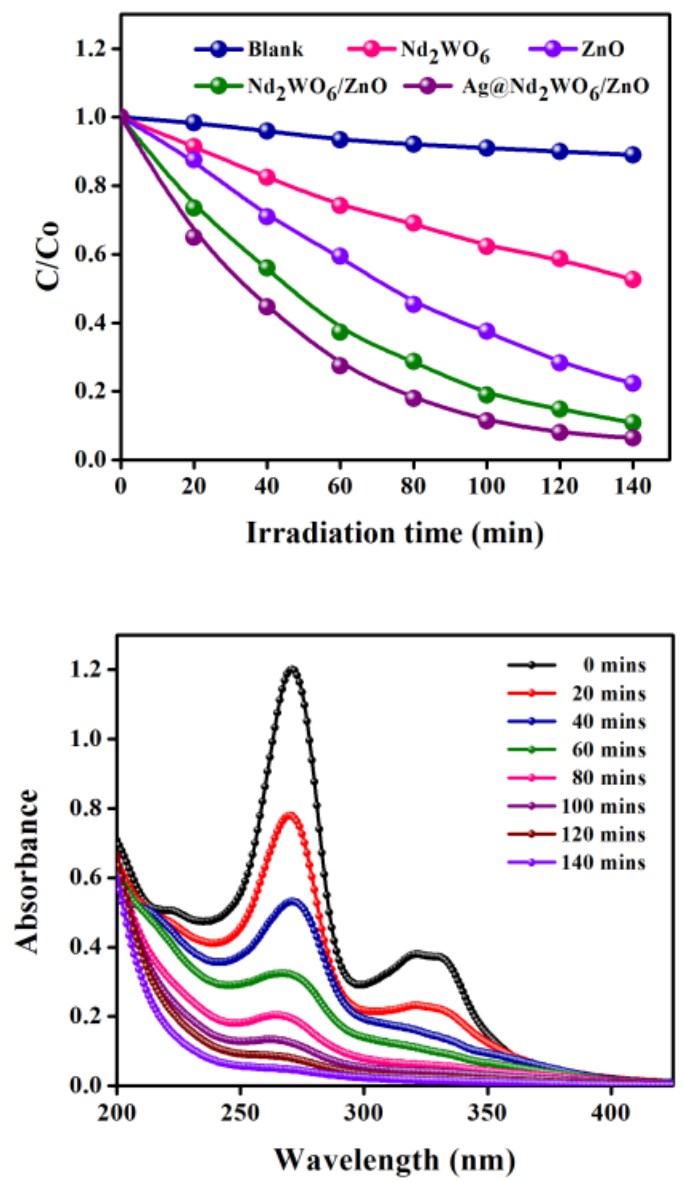

Fig. 6 i) Photocatalytic degradation of different catalyst, ii) Absorption spectrum CIP degradation

\section{B. The optimization of catalyst dosage}

The amount of catalyst is optimized to the degradation, at the time the efficiency of the degradation is almost increasing. An otherwise large amount of catalyst is used and the efficiency is decreased. Because the high amount of catalyst is added to the degradation process the surface area of the degradation material is increased which leads to an increase in the reactive sites [14].

Fig. 6 shows the catalyst loading (ANWZ: 20-50mg) of ANWZ nanocomposite. For the optimization dosage of photocatalytic degradation process $40 \mathrm{mg}$ of ANZ catalyst is needed to degrade the pollutant.

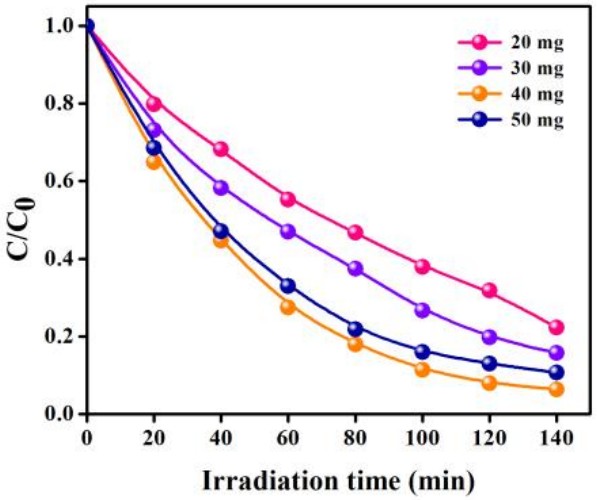

Fig. 7 Photodegradation of CIP under optimization of different catalyst dosage

\section{Optimization of concentration}

The optimization concentration of CIP is $20 \mu \mathrm{M}$ to $40 \mu \mathrm{M}$. The concentration of $40 \mu \mathrm{M}$ is the best to degrade the CIP pollutant. If the concentration of pollutant was increased, then the rate of degradation was decreased and it is shown in Fig. 7.

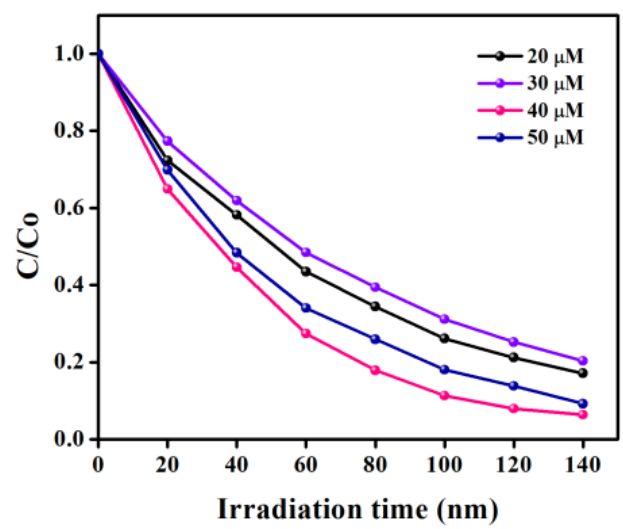

Fig. 8 Photodegradation of CIP with the optimized concentration

\section{Recyclability test}

After completion of degradation, the remaining reacting catalyst was collected, filtered and washed with water then dried. Further, it involves re-usability test.

The catalyst was tested recyclability to again and with five successive runs and it be shown in Fig. 8. In spite of this, the efficiency of CIP after the fifth cycle remains $86.22 \%$. After the fifth cycle, the catalyst contains good mechanical stability and corrosive resistance [15].

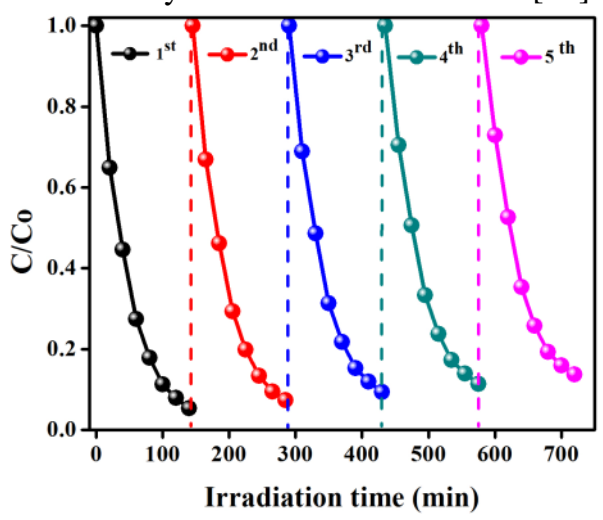

Fig. 9 Recycle efficiency of CIP degradation 


\section{CONCLUSION}

In summary, the ANWZ nanocomposite was prepared under hydrothermal method, and its spectral information's are explained detailed. The ANWZ photocatalyst is degraded CIP drug under visible light irradiation. The photocatalytic efficiency is higher in ANWZ catalyst than that of other undoped $\mathrm{ZnO}, \mathrm{Nd}_{2} \mathrm{WO}_{6}$, and $\mathrm{NWZ}$ nanocomposite. The spherically silver anchored on a cluster with nanorods structure was found in ANWZ Nanocomposite. By EDX analysis the presence of elements $\mathrm{Ag}, \mathrm{W}, \mathrm{Nd}, \mathrm{O}, \mathrm{Zn}$ and $\mathrm{C}$ is confirmed. The CIP was completely degraded within 140 minutes under Visible light irradiation with the efficiency of $95.54 \%$. The ANWZ photocatalyst contains superior chemical stability. After the re-cycle test, the efficiency of the catalyst is $86.22 \%$. Besides, the degradation process the antibacterial study is carriedout and the results antibacaterial activity is higher in Bacillus bacteria than the E.Coli bacteria.

\section{ACKNOWLEDGEMENT}

The author, M.A acknowledges Kalasalingam Academy of Research and Education for providing research fellowship and necessary facilities.

\section{REFERENCES}

[1] L.M. Pastrana-Martinez, J.L. Faria, J.M. Dona - Rodriguez, C. Fernandez-Rodriguez, A.M.T. Silva, Degradation of diphenhydramine pharmaceutical in aqueous solutions by using two highly active $\mathrm{TiO} 2$ photocatalysts: operating parameters and photocatalytic mechanism, Appl. Catal. B 113-114 (2012) 221-227.

[2] A.Ahmad, F.D.Daschner K. Kummerer, Biodegradability of cefotiam, ciprofloxacin, meropenem, penicillin G, and sulfamethoxazole and inhibition of wastewater bacteria, Arch. Environ. Contam. Toxicol. 37 (1999) 158-163.

[3] M. A. Rauf, M. A. Meetani, A. Khaleel, A. Ahmed, Photocatalytic degradation of Methylene Blue using a mixed catalyst and product analysis by LC/MS, Chem. Eng. J. 2010, 157, 373-378.

[4] T. Sreethawong, S. Chavadej, S. Ngamsinlapasathian, S. Yoshikawa, Sol-gel synthesis of a mesoporous assembly of $\mathrm{Nd} 2 \mathrm{O} 3$ nanocrystals with the aid of structure-directing surfactant, Solid State Sci. 10 (2008) 20-25.

[5] R. Bazzi, M.A. Flores-Gonzalez, C. Louis, K. Lebbou, C. Dujardin, A. Brenier, W. Zhang, O. Tillement, E. Bernstein, P. Perriat, Synthesis and luminescent properties of sub-5-nm lanthanide oxides nanoparticles, J. Lumin. 102 (2003) 445-450.

[6] M. Zawadzki, L. Kepin'ski, Synthesis and characterization of neodymium oxide nanoparticles, J. Alloys. Compd. 380 (2004) 255-259.

[7] T. Liu, Y. Zhang, H. Shao, X. Li, Synthesis and characteristics of Sm2O3 and Nd2O3nanoparticles, Langmuir 19 (2003) 7569-7572.

[8] U. Koch, A. Fojtik, H. Weller, A. Henglein, Photochemistry of semiconductor colloids. Preparation of extremely small $\mathrm{ZnO}$ particles, fluorescence phenomena and size quantization effects, Chem. Phys. Lett. 122 (1985) 507-510.

[9] S. Krishnamoorthy, A.A. Iliadis, T. Bei, P.G. Chrousos, An interleukin- $6 \mathrm{ZnO} / \mathrm{SiO} 2 / \mathrm{Si}$ surface acoustic wave biosensor, Biosens. Bioelectron. 24 (2008) 313-318.

[10] Y.L. Wang, H.S. Kim, D.P. Norton, S.J. Pearton, F. Ren, Dielectric passivation effects on $\mathrm{ZnO}$ light-emitting diodes, Appl. Phys. Lett. 92 (2008) 112101.

[11] M. R. S. Zaidan, A. Noor Rain, A. R. Badrul, A. Adlin, A. Norazah, I. Zakiah, In vitro screening of five local medicinal plants for antibacterial activity using disc diffusion method, Tropical Biomedicine, 22, 2005, 165-170.

[12] D. Xu, Y. Bai, Z. Li, Y. Guo, L. Bai, Enhanced photodegradation ability of solvothermal synthesized metallic copper-coated $\mathrm{ZnO}$ microrods, Colloids Surf. A 548 (2018) 19-26.

[13] M. Rani, U. Shanker, Sun-light has driven rapid photocatalytic degradation of Methylene blue by poly(methyl methacrylate)/metal oxide nanocomposites, Colloids Surf. A Physicochem. Eng. Asp. 559 (2018) 136-147.
[14] F.T. Li, Y. Zhao, Q. Wang, X.J. Wang, Y.J. Hao, R.H. Liu, D.S Zhao, Enhanced visible-light photocatalytic activity of active $\mathrm{A} 2 \mathrm{O} 3 / \mathrm{g}-\mathrm{C} 3 \mathrm{~N} 4$ heterojunctions synthesized via surface hydroxyl modification, J. Hazard.Mater. 283 (2015) 371-381.M .Wu, D. Atchley, L. Greer, S. Janssen, D. Rosenberg, J. Sass, “Dosed without prescription: preventing pharmaceutical contamination of our nation's drinking water," Natural Resources Defense Council White Paper, 60 (2009).

\section{AUTHORS PROFILE}

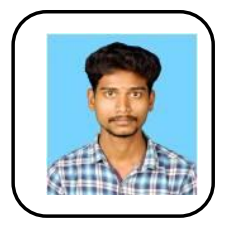

M. Arunpandian is a research scholar at Nanomaterial Laboratory, Department of Chemistry, International Research Centre, Kalasalingam Academy of Research and Education (Deemed to be University), Krishnankoil, India. $\mathrm{He}$ is working in the area materials Characterization, waste water purification and Photocatalysis.

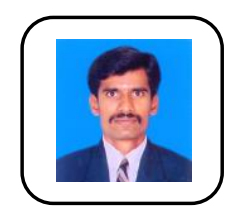

Dr. K. Selvakumar is a Postdoctoral Fellow at Nanomaterials Laboratory, Department of Chemistry, Kalasalingam Academy of Research and Education (Deemed to be University), Krishnankoil, India. Now, he is working on the Postdoctoral Researcher, Institute of Microstructure and Property of Advanced Materials, Beijing University of Technology, Ping Le Yuan, Chaoyang, Beijing, China. He has published 21 papers in peer-reviewed journal on the kinetics, organic synthesis and photocatalysis.

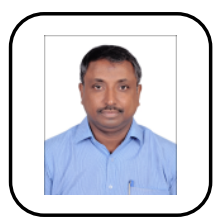

Dr. E. R. Nagarajan is Assistant Professor in Department of Chemistry, International Research Centre, Kalasalingam Academy of Research and Education (Deemed to be University), Krishnankoil, India. His area of research is Inorganic and Polymeric chemistry, Nanomaterials, Photocatalysis.

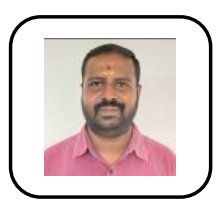

Dr. S. Arunachalam is Assistant Professor in Department of Chemistry, International Research Centre, Kalasalingam Academy of Research and Education (Deemed to be University), Krishnankoil, India. His area of Research is Inorganic and Bio-inorganic chemistry, Photocatalysis, etc. 